\title{
Lijst van gebruikte afkortingen
}

$\begin{array}{ll}\text { Alg. Secr. } & \text { Algemene Secretarie } \\ \text { ANRI } & \text { Arsip Nasional Republik Indonesia } \\ \text { BKI } & \text { Bijdragen tot de Taal-, Land-en Volkenkunde van Nederlands-Indië } \\ \text { CMC } & \text { Cultureel Maçonniek Centrum 'Prins Frederik' } \\ \text { ENI } & \text { Encyclopaedie van Nederlandsch-Indië } \\ \text { Gouv.bt } & \text { Gouvernementsbesluit } \\ \text { HMW } & \text { Hollandse Maatschappij der Wetenschappen } \\ \text { Jaarboek } & \text { Jaarboek [van het] Koninklijk Bataviaasch Genootschap } \\ \text { KB } & \text { Koninklijke Bibliotheek } \\ \text { KBG } & \text { Archief Bataviaasch Genootschap } \\ \text { KITLV } & \text { Koninklijk Instituut voor Taal-, Land- en Volkenkunde } \\ \text { Kol. } & \text { Archief Ministerie van Koloniën (Nationaal Archief Den Haag) } \\ \text { KZGW } & \text { Koninklijk Zeeuws Genootschap der Wetenschappen } \\ \text { NA } & \text { Nationaal Archief (Den Haag) } \\ \text { NNBW } & \text { Nieuw Nederlandsch Biografisch Woordenboek } \\ \text { Notulen } & \text { Notulen van de algemeene en bestuurs-vergaderingen van het } \\ & \text { Bataviaasch Genootschap } \\ \text { OIOC } & \text { Oriental and India Office Collections (Londen) } \\ \text { Perpusnas } & \text { Perpustakaan Nasional (Jakarta) } \\ \text { RANH } & \text { Rijksarchief Noord-Holland } \\ \text { RAZ } & \text { Rijksarchief Zeeland } \\ \text { TBG } & \text { Tijdschrift voor Indische Taal-, Land-en Volkenkunde } \\ \text { TNI } & \text { Tijdschrift voor Neêrland's Indië } \\ \text { TvG } & \text { Tijdschrift voor Geschiedenis } \\ \text { UBA } & \text { Universiteitsbibliotheek Amsterdam } \\ \text { UBL } & \text { Universiteitsbibliotheek Leiden } \\ \text { VBG } & \text { Verhandelingen van het Bataviaasch Genootschap } \\ \text { WNT } & \text { Woordenboek der Nederlandsche Taal } \\ & \end{array}$


Hans Groot - 9789004253803

Downloaded from Brill.com $\odot 4 / 26 / 2023$ 02:33:11PM via free access 


\section{BIJLAGE 1}

\section{Leden en vergaderingen}

Leden Bataviaasch Genootschap 1779-1794

\begin{tabular}{lrrrrrrr}
\hline & 1779 & 1780 & 1781 & 1786 & 1790 & 1792 & 1794 \\
\hline Directeuren & 16 & 16 & 13 & 13 & 14 & 13 & 18 \\
Dirigerende leden & 9 & 9 & 9 & 8 & 8 & 7 & 10 \\
Leden in Batavia & 94 & 90 & 87 & 87 & 90 & 83 & 92 \\
Leden op de buitenkantoren & 73 & 86 & 98 & 98 & 97 & 92 & 84 \\
\cline { 2 - 7 } Totaal & 192 & 201 & 207 & 206 & 209 & 195 & 204 \\
\hline
\end{tabular}

Opgave volgens de Verhandelingen 1-7 


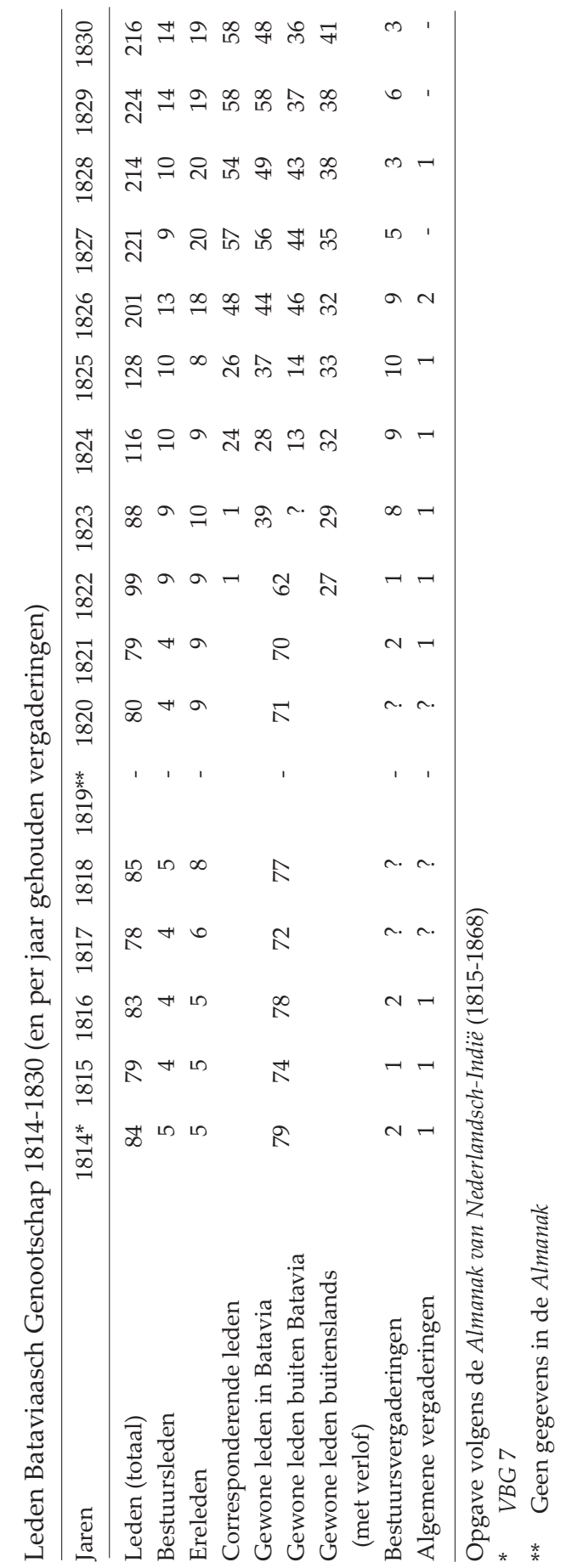




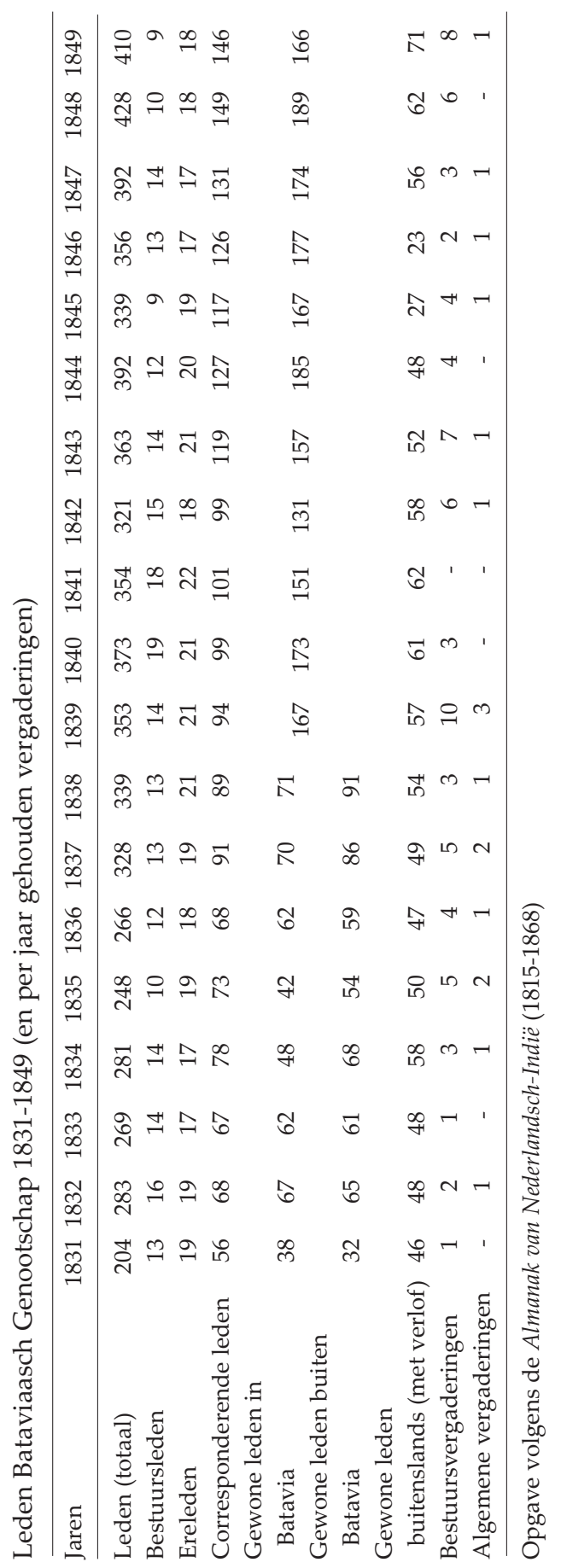




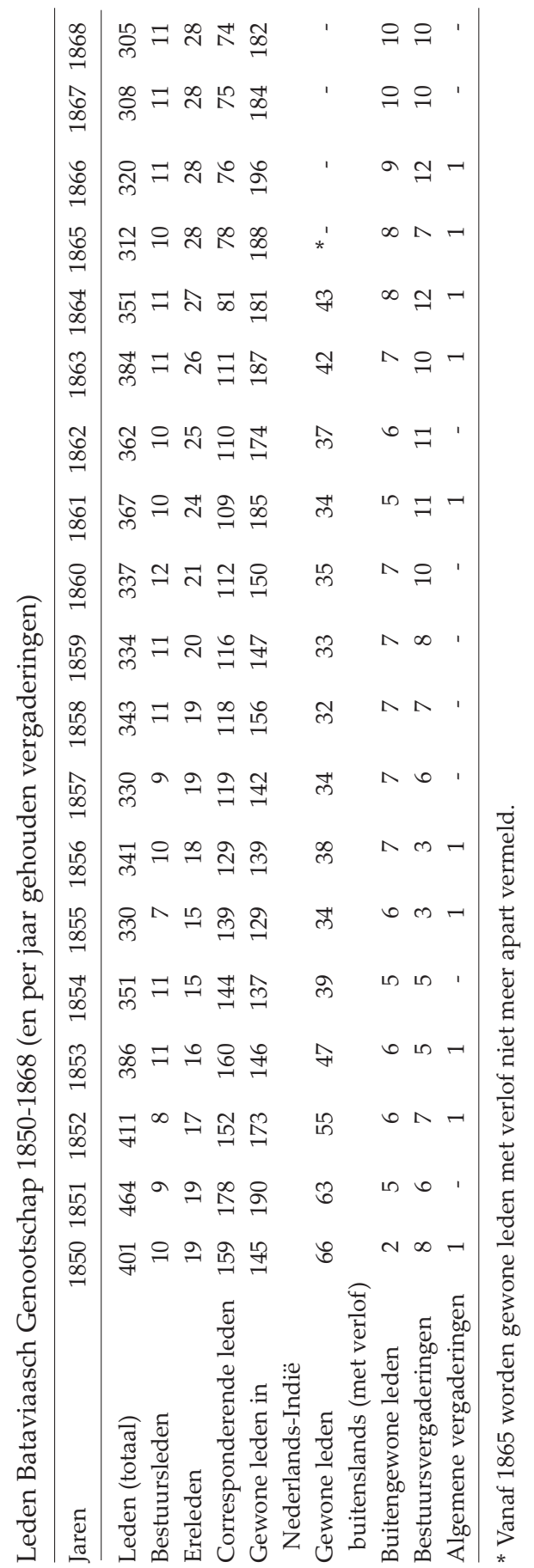




\section{Bijlage 2}

\section{Drukwerk van de pers van het Bataviaasch Genootschap 1843-1848}

\section{Toelichting}

Deze lijst bevat het traceerbare drukwerk, dat in de jaren 1843-1848 van de persen van het Bataviaasch Genootschap is gekomen. Daarbij moet opgemerkt dat een mogelijk grotere hoeveelheid 'stukken van geringen omvang, welke slechts tot bepaalde einden voor den handel en ten gerieve van particulieren moeten dienen, zoo als manifesten, rekeningen, uitklaringen, catalogussen en dergelijke' niet traceerbaar is, vanwege het vluchtige karakter ervan. Omdat voor dit vluchtige drukwerk toestemming was verleend en het conflict met het gouvernement juist om het 'andere' drukwerk ging, is dat in de lijst opgenomen. Op grond van deze lijst is het mogelijk een indruk te krijgen van de hoeveelheid werk die in de drukkerij werd verzet. Voor het overige zij verwezen naar hoofdstuk 5 .

Van de met een asterisk $\left({ }^{*}\right)$ gemerkte titels heb ik geen exemplaar in handen gehad.

Seriewerken, zoals de Verhandelingen, jaarlijkse verslagen en tijdschriften, zijn onder het jaar van uitkomen telkens opnieuw opgenomen.

1 Extract uit het register der Handelingen en Resolutien van besturende leden van het Bataviaasch Genootschap van Kunsten en Wetenschappen.

[Ter drukkerij van het Bataviaasch Genootschap, na 20 juli 1843] 8 $8^{\circ} 15 \mathrm{p}$. ANRI ABG 196 bij verg. 20-7-1843, punt 6.

2 Extract uit het register der Besluiten van den Gouverneur Generaal van Nederlandsch Indië.

[Ter drukkerij van het Bataviaasch Genootschap, na 5 oktober 1843] $8^{\circ} .3 \mathrm{p}$. ANRI ABG 196 bij verg. 20-7-1843.

3 S.A. Buddingh, Kerkelijke toespraak aan de hervormde en luthersche gemeenten, bij gelegenheid der inwijding van het orgel in de Willemskerk te Batavia, op den 16den Julij 1843 gehouden door Dr.S.A. Buddingh, V.D.M. Uitgegeven tot ondersteuning van een behoeftig huisgezin.

Ter drukkerij van het Bataviaasch Genootschap. 1843. $8^{\circ} .32$ p.

Voorwoord van de schrijver gedateerd: 16-10-1843.

KITLV q 228; Perpusnas XXIX 30 
Bijwet voor de Z.A. Loge De Ster in het Oosten, werkende in het O. van Batavia. [vignet]

Ter drukkerij van het Bataviaasch Genootschap. 1843. $8^{\circ} .62$ p.

KITLV dd 128 (fotokopie Bibl.Theol. coll. S.J. Maastricht 3190 E 41)

5 W.R. van Hoëvell, Verslag van den staat der werkzaamheden van het Bataviaasch Genootschap van Kunsten en Wetenschappen, gelezen in de algemeene vergadering des genootschaps op den 5den october 1843. Door W.R. van Hoëvell, VicePresident des Genootschaps.

Ter drukkerij van het Bataviaasch Genootschap. 1843. $8^{\circ} .72+$ II p.

KITLV dd 929; Perpusnas B 32/3

6 Verhandelingen van het Bataviaasch Genootschap van Kunsten en Wetenschappen. 19de deel. Batavia [drukkerij van het Bataviaasch Genootschap] 1843.

$8^{\circ}$. ii + xcviii + iv $+128+$ xlii $+167+422$ p.

KITLV leeszaal; Perpusnas B 25/19.

(Van de teksteditie Sjaïr Bidasari is de Maleise tekst gezet en gedrukt door de Landsdrukkerij, de rest van het deel is gedrukt op de pers van het Bat. Gen.)

$7 \quad$ The tenth Annual Report of the board of directors of the Parapattan Orphan Asylum; founded in the year 1832, for the board, clothing, and education of the orphans and other children, left destitute in this part of India. Translated from the Dutch. Printed at the press of the Batavia Society of Arts and Sciences. 1843. $8^{\circ} .29$ p. Perpusnas B 316 - 1843 Eng.

(Nederlands origineel gedrukt door Ukena \& Co, Batavia 1843.)

1 Sjaïr Bidasari, oorspronkelijk Maleisch gedicht, met eene Vertaling en Aanteekeningen; uitgegeven door W.R. van Hoëvell, theol. Doct., Vice-President van het Bataviaasch Genootschap en Predikant te Batavia. [vignet]

Batavia, ter drukkerij van het Bataviaasch Genootschap. 1844.

$8^{\circ} .2$ delen. Dl. 1: ii + xlii +167 (Maleise tekst gedrukt door de Landsdrukkerij)

D1. 2: 421 + ii. Titeluitgave van VBG 91, 1843 no 6, 2e stuk.

KITLV hh 689; Perpusnas XXXII 97

2 Tijdschrift voor Neêrland's Indië. Zesde jaargang.

Batavia, ter drukkerij van het Bataviaasch Genootschap. 1844.

8․ 4 delen. Dl. 1: 570 p. Dl. 2: 442 p. Dl. 3: 348 p. Dl. 4: 396 p.

KITLV leeszaal; Perpusnas A191/1844

3 Natuur-en Geneeskundig Archief voor Neêrland's Indië. Eerste jaargang.

Batavia, ter drukkerij van het Bataviaasch Genootschap. 1844. $8^{\circ}$. xii + vi + $639 \mathrm{p}$.

KITLV TS 511 [K $61 \mathrm{C}]$

4 Bijdragen tot de geneeskundige topographie van Batavia. Door P. Bleeker; Offic. van Gezondh. bij het Geneesk. Bestuur in Nederl. Indië, lid en bibliothecaris van het Bataviaasch Genootschap van Kunst. en Wetensch. 2 stukken. [vignet]

Batavia, ter drukkerij van het Bataviaasch Genootschap. $1844.8^{\circ}$. ii +80 p. en 169-220.

KITLV 632 C 5; Perpusnas XXI 623. Overdrukken uit Natuur-en Geneeskundig Archief 1, 1844 no 3, p. 1-80 en 169-220. 
Eerder ook verschenen in TNI 1843, 2, p. 281-332, 640-58 en TNI 1844, 1, p. 45178, en 2, 97-140.

5 Bijdrage tot de kennis der genees- en artsenijmengkunde onder de Chineezen in het algemeen en onder die te Batavia in het bijzonder, door P. Bleeker. [vignet]

Batavia: ter drukkerij van het Bataviaasch Genootschap. 1844 . $8^{\circ}$. ii + p. $257-$ 284.

UBL 607 B 8. Overdruk uit 1844, 3?

P. Mijer, Gedenkboek der feestelijke vereeniging van oud-studenten der vaderlandsche hoogeschoolen, gehouden te Batavia, den tweeden augustus 1844. Uitgegeven ten voordeele van het Weeshuis te Parapattan.

Batavia, ter drukkerij van het Bataviaasch Genootschap. $1844.8^{\circ}$. vi + $190+\mathrm{ii}+5$ lithografieën.

KITLV dd 21; Perpusnas XXII 502

Studentenliederen gezongen op het oud-studentenfeest, gevierd te Batavia op den 2den Augustus, 1844. [vignet]

Batavia, ter drukkerij van het Bataviaasch Genootschap, 1844. $8^{\circ} .24$ p.

KB 6 F 7. (Titeluitgave van deel III van Gedenkboek, 1844 no 7, zie hierboven)

8 De Nachtwacht, blijspel in één bedrijf, naar het hoogduitsch van Theodor Körner, door S. van Deventer, JSzoon. [vignet]

Batavia, ter drukkerij van het Bataviaasch Genootschap. $1844.8^{\circ} 47 \mathrm{p}$.

UBL 1097 C 82

9 Verslag der feestviering van het vijf en zeventig-jarig grondwettig bestaan der vrijmetselarij te Batavia, gehouden op den 16den November 1844 (g.s.) [vignet]

Batavia, ter drukkerij van het Bataviaasch Genootschap. $8^{\circ} .104 \mathrm{p}$.

CMC Den Haag; Perpusnas 345 a 12

10 Elfde jaarlijksch verslag der directie van het weeshuis te Parapattan, opgerigt in 't jaar 1832, voor de voeding, kleeding en opvoeding van weezen en andere verlatene kinderen in dit gedeelte van Indië. Eleventh Annual Report etc.

Ter drukkerij van het Bataviaasch Genootschap van kunsten en wetenschappen. 1844.

$8^{\circ} .67 \mathrm{p}$.

Perpusnas B 3161844 (Engelse en Nederlandse tekst)

*11 Bouchardy, Lazaro. Tooneelspel in vier bedrijven, met een voorspel; naar het Fransch: Lazare le patre.

Batavia, ter drukkerij van het Bataviaasch Genootschap. 1844. $8^{\circ} 3+204$ p.

Van der Chijs, Proeve, p, 76, no 18.

Perpusnas XL 105, echter niet beschikbaar.

12 W.C.H. toe Water, Nagelaten leerreden van wijlen -, theol.doct. en predikant te Semarang. Uitgegeven en van een levensberigt voorzien door W.R. van Hoëvell, theol. doct. en predikant te Batavia.

Batavia, ter drukkerij van het Bataviaasch Genootschap. 1844. $8^{\circ}$. [xii] + xxxviii + $[2]+235 \mathrm{p}$.

Perpusnas XXIX 64

13 Wiwoho of Mintorogo, een Javaansch gedicht uitgegeven en van eene vertaling en aantekeningen voorzien door J.F.C. Gericke.

$8^{\circ}$. ii + xxxiii $+98+179$ (Javaanse en Nederlandse tekst)

Perpusnas xxxiii 112. Titeluitgave van VBG 20, 1845 no 1, 2e stuk 
Perpusnas XXXIII 3 en XXXIII 81 alleen Javaanse tekst op groot papier, $176 \mathrm{p}$.

${ }^{*} 14$ Alphabetisch woordenlijstje en vertaling van al de woorden die voorkomen in het Fransch lees- en vertaalboekje, door G. Verhulp.

Batavia, drukkerij van het Bataviaasch Genootschap. $12^{\circ} .55 \mathrm{p}$.

Van der Chijs, Proeve, Supplement 1, p. 37; niet in de catalogus Perpusnas

*15 Catalogus eener belangrijke verzameling van vogels toebehoorende aan het Bataviaasch Genootschap van Kunsten en Wetenschappen, welke verkogt zal worden op de 3den Junij 1844, in een der zalen van de Harmonie.

Ter drukkerij van het Bataviaasch Genootschap. 1844

Perpusnas catalogusnummer XLII 247, echter niet beschikbaar.

1 Verhandelingen van het Bataviaasch Genootschap van Kunsten en Wetenschappen. 20e deel.

Batavia, [drukkerij van het Batviaasch Genootschap] 1844 [maar verschenen in 1845].

$8^{\circ}$ ii + vi $+94+$ xxxiii $+175+98$ p.

KITLV leeszaal; Perpusnas B 25 / 20

(Van de teksteditie van Wiwoho in dit deel is de Javaanse tekst gezet en gedrukt door de Landsdrukkerij, de rest van het deel is gedrukt door de pers van het Bat. Gen.)

2 Tijdschrift voor Neêrland's Indië. Zevende jaargang.

Batavia, ter drukkerij van het Bataviaasch Genootschap. 1845.

$8^{\circ} 4$ dln. Dl. 1: 422 p. Dl. 2: 570 p. Dl. 3: 484 p. Dl. 4.461 p.

KITLV leeszaal; Perpusnas A 1911845

3 Natuur-en Geneeskundig Archief voor Neêrland's Indië. Tweede jaargang.

Batavia, ter drukkerij van het Bataviaasch Genootschap. 1845. $8^{\circ}$. iv + vi + $711 \mathrm{p}$.

KITLV TS 511 [ K 61 C]

$4 \quad$ Nieuwe Indische verhalen en herinneringen uit vroegeren en lateren tijd, door W.L. Ritter. I. Deel / II. Deel.

Batavia, ter drukkerij van het Bataviaasch Genootschap. 1845. $8^{\circ}$. Dl. 1: [vi] + iv + 267 p. Dl. 2: [iv] + ii + 299 p.

KITLV cc 37

5 Twaalfde jaarlijksch verslag van de directie van het weeshuis te Parapattan, opgerigt in 't jaar 1832, voor de voeding, kleeding en opvoeding van weezen en andere verlatene kinderen in dit gedeelte van Indië. Twelfth Annual Report etc.

Batavia, ter drukkerij van het Bataviaasch Genootschap. [1845]. $8^{\circ} .54$ p.

Perpusnas B 3161845 (Engelse en Nederlandse tekst)

${ }^{*} 6$ Verslag van het lijkfeest, gehouden in de Z.A. Loge De Ster in het Oosten, gevestigd te Batavia. [B.H.M. de Kock]

Batavia, ter drukkerij van het Bataviaasch Genootschap, 1845. $8^{\circ} .34$ p.

Van der Chijs, Proeve, p. 79, no. 30.

Perpusnas B 345 a1, echter niet beschikbaar.

*7 Catalogus der boekwerken, enz. van de Z.A. Loge De Ster in het Oosten. 
Batavia, drukkerij van het Bataviaasch Genootschap. 1845. $8^{\circ} .28$ p.

Van der Chijs, Proeve, Supplement 1, p. 38. Niet in catalogus Perpusnas.

*8 W.C.H. toe Water, Nagelaten leerredenen. 2e dr

Batavia, drukkerij van het Bataviaasch Genootschap. 1845

Van der Chijs, Proeve, Supplement 2 p. 45. Niet in catalogus Perpusnas.

9 P. Bleeker, Brieven over Java; door Bleeker. (Et parva utilia.) [vignet].

Batavia, 1845. (1e serie) $8^{\circ}$. iv + 207-40, 353-61, 381-427, 1-17, 19-28, 4 tabellen.

Perpusnas XXI 231

(Overdruk uit TNI 7 (1845) dl. 1-3. Impressum geeft geen drukkersnaam.)

1 P. Bleeker, Bibliothecae Societatis Artium Scientiarumque Quae Bataviae floret, Catalogus Systematicus curante Bleeker. [vignet]

Typis Societ. Art. Scient. Batav. 1846. 8․ $8+85$ p.

KITLV bb 76

2 Tijdschrift voor Neêrland's Indië. Achtste jaargang.

Batavia, ter drukkerij van het Bataviaasch Genootschap. 1846.

8․ Dl. 1: 399 p. Dl. 2: 606 p. Dl. 3: 400 p. Dl. 4: 394 p.

KITLV leeszaal; Perpusnas A 191

3 Natuur-en Geneeskundig Archief voor Neêrland's Indië. Derde jaargang.

Batavia, ter drukkerij van het Bataviaasch Genootschap, 1846. $8^{\circ}$. iv $+v+$ plano +617 .

KITLV TS 511

4 Tijdschrift ter bevordering van Christelijken zin in Neêrland's Indië. Onder medewerking van de heeren predikanten in Neêrland's Indië, en ten voordeele van het weeshuis te Parapattan uitgegeven door Dr. W.R. van Hoëvell, Theol. Doct. en Predikant te Batavia.

Batavia, ter drukkerij van het Bataviaasch Genootschap. 1846-47. (alleen jaargang 1 verschenen, titelpagina verzameldeel heeft 1846-1847, maar aflevering 4 heeft apart titelblad met 1846]

$8^{\circ}$. Dl. 1: iv $+i v+x v+i i+154$ p. Dl. 2: $i i+i i+i v+176$ p. Dl. $3: i i+i i+171$ p. Dl 4: $\mathrm{ii}+\mathrm{ii}+192+1 \mathrm{p}$.

KITLV TS 512

5 Desiderata van het Bataviaasch Genootschap van Kunsten en Wetenschappen. [vignet]

Batavia, ter drukkerij van het Bataviaasch Genootschap. 1846. $8^{\circ}$. ii + ii +34 p.

KB Broch. 1024

6 Verslag van het verhandelde in de algemeene vergadering van het Nederlandsch OostIndisch Bijbelgenootschap. Op donderdag de 9den Julij 1846, des avonds ten zeven ure, in de Willemskerk te Batavia.

Batavia, ter drukkerij van het Bataviaasch Genootschap. 1846. $8^{\circ} .70$ p.

KITLV q 44

7 De doodstraf getoetst aan gezonde rede en menschkunde, aan godsdienst en redelijkheid, aan maatschappelijk belang, aan bijbel en evangelie. Door S.A. Buddingh. (De opbrengst der uitgave is bestemd voor het genootschap tot zedelijke verbetering 
der gevangenen.)

Batavia, ter drukkerij van het Bataviaasch Genootschap. 1846. $8^{\circ}$ [iv] + 54 p. KITLV Z 142; Perpusnas XXVII 63

8 J.T. Canter Visscher, Index op het Staatsblad van Neêrland's Indië; loopende van 1816 tot 1844; gevolgd van eene chronologische opgave der bepalingen, die door latere verordeningen of door tijdsverloop als vervallen kunnen beschouwd worden; opgemaakt en met toestemming van het gouvernement uitgegeven door J.T. Canter Visscher, President van het Collegie van Boedelmeesters te Batavia. [vignet]

Batavia, ter drukkerij van het Bataviaasch Genootschap. 1846. $4^{\circ} \mathrm{x}+\mathrm{ii}+151 \mathrm{p}$. UBL 3929 A 50

9 De inwijding der Christenkerk te Serang, hoofdplaats der residentie Bantam, op den 20sten September 1846, door W.R. van Hoëvell.

Batavia, ter drukkerij, van het Bataviaasch Genootschap. 1846. $8^{\circ}$. ii +38 p.

KITLV q 38; Perpusnas XXIX 221

10 De bijbel in Indië. Redevoering gehouden in de algemeene vergadering van het Nederlandsch Oost-Indisch Bijbelgenootschap, op donderdag den 9den Julij, des avonds ten zeven ure, in de Willemskerk te Batavia, door W.R. van Hoëvell. [vignet]

Batavia, ter drukkerij van het Bataviaasch Genootschap. 1846. $8^{\circ} .52$ p.

KITLV q 275

11 Oost-Indische bloempjes. Gedichtjes voor de Nederlandsch-Indische jeugd, door J. van Soest.

Batavia, ter drukkerij van het Bataviaasch Genootschap. 1846. $8^{\circ}$. viii +109 p. UBA 1044 D 10, UBL 1293 F 50

12 Verzameling der Battahsche wetten en instellingen in Mandheling en Pertibie, gevolgd door een overzigt van land en volk in die streken; door T.J. Willer. [vignet]

Batavia, ter drukkerij van het Bataviaasch Genootschap. 1846. $8^{\circ}$. [ii] + vi + $280 \mathrm{p}$.

KITLV c 138

(Titeluitgave, zie ook TNI 8 (1846) dl 2, p. 145-424, 606.)

13 Welkom in het weeshuis te Parapattan. Een liedje aan Z. Excell. den Heere J.J. Rochussen, Minister van Staat, Gouverneur Generaal van Neêrland's Indië, bij hoogstdeszelfs bezoek in genoemd gesticht, op dinsdag den 20sten Januarij 1846, toegezonden door de weezen. [vignet]

Batavia, ter drukkerij van het Bataviaasch Genootschap. 1846. $8^{\circ} \mathrm{ii}+4 \mathrm{p}$.

KITLV dd 247

14 Hoe oud zijt gij? Godsdienstige overdenking naar Genesis 47: 8b; door S.A. Buddingh, Theol. Doct. en Predikant te Batavia. [vignet]

Batavia, ter drukkerij van het Bataviaasch Genootschap. 1846. $8^{\circ}$ ii +32 p. KB 1162 B 50

15 S.A. Buddingh, Geschiedkundig overzigt van het Bataviaasch Genootschap van Kunsten en Wetenschappen, voorgelezen in de algemeene vergadering van het genootschap op den 14den januarij 1846.

Batavia [drukkerij van het Genootschap] 1846. $8^{\circ}$. p. 259-275.

KITLV dd 766; Perpusnas XXII 313

(Overdruk van TNI 8 (1846) dl 1) 
Dertiende jaarlijksch verslag van de directie van het weeshuis te Parapattan, opgerigt in 't jaar 1832, voor de voeding, kleeding en opvoeding van weezen en andere verlatenen kinderen in dit gedeelte van Indië. Thirteenth Annual Report etc. Batavia, ter drukkerij van het Bataviaasch Genootschap. 1846. $8^{\circ} .80+4$ p. Perpusnas B 3161847 (Engelse en Nederlandse tekst, beschadigd exemplaar, titelpagina en p. 3-6 ontbreken, titel analoog aan serie overgenomen.)

1735 Statements of exports from Java and Madura for as many articles of trade, being mostly, if not all, the produce of Netherland's India with indication of countries whereto; from the beginning of 1825 to the end of the year 1845. Extracted from the yearly government reports, and published for the benefit of the Batavia Parapattan Orphan Asylum, by a member of the direction for that asylum, in August 1846. 35 Etats d'exportations etc.

Geen drukker vermeld, maar mogelijk ook gedrukt bij het BG gezien: 'and published for the benefit of the Batavia Parapattan orphan asylum, by a member of the direction of that asylum'. $4^{\circ}$. oblong, 30 dubbelbladen.

Perpusnas XXVI 792 (ex. met opdracht voor W.R. van Hoëvell door F. Embrechts, die de staten compileerde.)

18 S.L. Heymann, Opmerkingen over de acclimatisatie. door -, Dirigerend officier van gezondheid. [vignet].

Batavia, ter drukkerij van het Bataviaasch Genootschap. 1846. $8^{\circ}$. p. 311-359

Overdruk uit Natuur- en Geneeskundig Archief 3 (1846).

Perpusnas XX 136 (geen titelblad, wel gedrukt omslag)

19 [J.J.L.L.] Jacobson, Bijdrage tot de theekultuur, door -. Batavia, ter drukkerij van het Bataviaasch Genootschap. 1846. $8^{\circ} .30$ p. met twee ingevoegde tabellen

Overdruk TNI 8 (1846) dl 2.

Perpusnas XI 132

1 Verhandelingen van het Bataviaasch Genootschap van Kunsten en Wetenschappen. 21ste deel. 1e gedeelte / 2e gedeelte. [vignet]

Batavia, ter drukkerij van het Bataviaasch Genootschap. 1846-1847. [maar gezien het voorwoord pas verschenen in 1847]. $8^{\circ}$. Dl. 1 : ii $+115+60+33+12+$ xxviii + $131 \mathrm{p}$.

D1. 2: ii $+28+596$ p.

KITLV leeszaal; Perpusnas B 25/21

2 Tijdschrift voor Neêrland's Indië. Negende jaargang.

Batavia, ter drukkerij van het Bataviaasch Genootschap. 1847. $8^{\circ}$. Dl. 1: 388 p. Dl. 2: 428 p. Dl. 3: 392 p. Dl. 4: 574 p.

KITLV leeszaal; Perpusnas A 191

3 Natuur-en Geneeskundig Archief voor Neêrland's Indië. Vierde jaargang.

Batavia, ter drukkerij van het Bataviaasch Genootschap, 1847.

$8^{\circ} .2$ afl. verschenen. $255 \mathrm{p}+$ plano.

KITLV TS 511

4 Twaalftal kerkelijke reden, van S.A. Buddingh, Theol. Doct. en Predikant te Batavia. Uitgegeven ten voordeele van het Parapattan-Weezen-gesticht. [vignet]

Batavia, ter drukkerij van het Bataviaasch Genootschap. 1847. $8^{\circ}$. ii + xviii + i + i 
$+\mathrm{iii}+\mathrm{ii}+261 \mathrm{p}$.

KB 3190 D 31; Perpusnas XXIX 63 (ex. op groot papier)

5 Veertiende jaarlijksch verslag van de directie van het Parapattan Weezen Gesticht, opgerigt in 't jaar 1832, voor de voeding, kleeding en opvoeding van weezen en andere verlatene kinderen in dit gedeelte van Indië. Fourteenth Annual Report etc.

Batavia, ter drukkerij van het Bataviaasch Genootschap. 1847. $8^{\circ} .83$ p. met litho's

UBL V 8701846 (14) [1847]

6 Zeemans-gids voor de straten Banka en Gaspar, door H.D.A. Smits. Uitgegeven van wege de kommissie tot verbetering der Indische zee-kaarten, enz. [vignet]

Batavia, ter drukkerij van het Bataviaasch Genootschap. 1847. $4^{\circ}$. xvi $+56+$ [i] p.

KITLV x 122

$7 \quad$ Onderzoek naar de reden, waarom Jezus verboden heeft hem als den Christus openbaar te maken. Door S.A. Buddingh, Theol.Doct. en Pred. te Batavia.

Batavia, ter drukkerij van het Bataviaasch Genootschap, 1847. $8^{\circ} .40$ p.

Perpusnas XXIX 512

8 M. Mistral, Chronique théatrale concernant monsieur Robert, directeur du théatre Français à Batavia.

Batavia, Imprimerie de Lange \& Co. 1847. [maar gedrukt op de pers van het BG].

$8^{\circ} 12 \mathrm{p}$.

Perpusnas B $342 \mathrm{p}$

*9 Hikayat Sultan Abdoel Moeloek, uitgegeven en vertaald door P.P. Roorda van Eysinga.

Batavia, ter drukkerij van het Bataviaasch Genootschap. 1847. $8^{\circ} .150$ p. (alleen Maleise tekst?)

Van der Chijs, Proeve, p. 84, no 32

(Gedeeltelijke titeluitgave van editie in TNI 9 (1847), dl. 4. p. 285-526)

Perpusnas XXXII is editie 1858 van hetzelfde werk.

10 Verzameling van eene menigte noodzakelijke zamenspraken met inlanders van allerlei klassen, in de laag Maleische taal; voorafgegaan door een beknopte spraakkunst dier taal; zoo als dat alles door den lageren Maleijer wordt gesproken en verstaan, en zulks tot gemak van velen; door [W.A.P. Roorda van Eysinga].

Batavia, ter drukkerij van Lange \& Co. 1847. [maar gedrukt op de persen van het BG].

$12^{\circ}$. viii $+80 \mathrm{p}$.

Perpusnas XLVI 699

*11 W.R. van Hoëvell, Geloofshelden uit de eerste eeuwen van de christelijke kerk.

Batavia, ter drukkerij van het Bataviaasch Genootschap. 1847. $8^{\circ} .84$ p.

(Overdruk uit Tijdschrift ter bevordering van christelijken zin, 1e jg, iii, p. 97.)

Van der Chijs, Proeve, Supplement 1, p. 39. Niet in catalogus Perpusnas.

12 Bijdragen tot de kennis van de nopal-kultuur en van de cochenelle-teelt op Java; door L. Monod de Froideville.

Batavia, ter drukkerij van het Bataviaasch Genootschap. 1847. $8^{\circ}$. ii $+78+$ tabel en gedrukt omslag. 
Perpusnas XI 118

(Titeluitgave van TNI 9 (1847), dl 2, p. 207-84, 299.)

13 [Romo, een Javaansch gedicht naar de bewerking van Joso Dhipoero, uitgegeven en vertaald door C.F. Winter.] Titelpagina ontbreekt

(Titeluitgave van 1847 / 1, 2e deel. (alleen de Javaanse tekst) $8^{\circ} .596$ p.

Perpusnas XXXIII 28

14 CXXVI Tableaux, démontrant le commerce de l'ile de Java avec 38 différents pays, tant pour les importations que les exportations, de 1825 à 1845. Extraits des rapports annuels du gouvernement par F.A.E. [= Embrechts] de Batavia. CXXVI Statements, showing the trade of Java with 38 different countries etc.

Batavia, à l'imprimérie de la Société Batave des Arts et des Sciences. f ${ }^{\circ} .105$ p. Perpusnas $24^{*}$

$1 \quad$ Warnasarie 1848. Letterkundig jaarboekje uitgegeven door I. Munnich.

[Batavia, drukkerij van het Bataviaasch Genootschap] 1848. $8^{\circ}$. [i] + [i] + 299 p. KITLV cc 31

2 Tijdschrift voor Neêrland's Indië. Tiende jaargang.

Batavia, ter drukkerij van het Bataviaasch Genootschap. 1848. $8^{\circ} .1$ deel verschenen. 399 p.

KITLV leeszaal; Perpusnas A 191/1848.

3 Ontleed-en natuurkundige beschouwingen over het menschelijk ligchaam en leeven, naar aanleiding van demonstratiën op het kunstkadaver van Dr. Anzoux, gehouden in het Bataviaasch Genootschap van Kunsten en Wetenschappen door J. Munnich, Officier van Gezondheid. Uitgegeven ten voordeele van het Parapattan-Weeshuis te Batavia. Eerste deel [ niet verder verschenen]

Batavia, ter drukkerij van het Bataviaasch Genootschap. 1848. $8^{\circ}$ vi + ix + $436 \mathrm{p}$.

\section{UBA 658 F 1}

4 Versjes gezongen bij het examen door de weezen van het Parapattan Weezen-Gesticht, in de Willemskerk op den 10den Mei 1848. [vignet]

Batavia, ter drukkerij van het Bataviaasch Genootschap. 1848. $8^{\circ} .8$ p.

KITLV dd 248

$5 \quad$ Inwendige comsumptie van zout [op] Java en Madura, van af 1827 tot en met 1847. Uitvoer van zout van Java en Madura, van af 1814 tot 1847. Met nog eenige andere inlichtingen omtrent het artikel zout. [vignet]

Batavia, ter drukkerij van het Bataviaasch Genootschap. 1848. $\mathrm{f}^{\circ}$. [i] +8.

KITLV o 202

6 Zeemansgids voor de eilanden en vaarwaters beoosten Java, gevolgd door eene methode, om door hoekmeting nabij de oppervlakte der zee, de hoogten van bergen en omgekeerd hunnen afstanden te berekenen; door H.D.A. Smits, luitenant-ter-zee 2 de klasse, belast met het beheer van het depot zeekaarten, boeken, enz. secretaris der kommissie tot verbetering der Indische zeekaarten. [vignet] Batavia, ter drukkerij van het Bataviaasch Genootschap. 1848.

A seaman's guide for the islands and straits eastward of Java, etc.

$4^{\circ} . i+x i+x i+54+54+i+i+8+8+17+1 p$. 
UBL 1856 C 16 (Nederlandse en Engelse tekst)

$7 \quad$ Wat belooft de water-geneeskunde voor de gezondheid en welvaart van het Europesche ras in tropische gewesten? Door F.A.C. Waitz, Med.Dr. Uitgegeven ten voordeele van het Parapattan weezen-gesticht op Rijswijk.

Batavia, ter drukkerij van het Bataviaasch Genootschap. 1848. $8^{\circ}$ [viii] $+180 \mathrm{p}$. KITLV z 49

8 Geschiedenis van Sultan Abdoel Moeloek, Koning van Barbarije. Bezongen in het hedendaagsch Djohorsch Maleisch door zijne hoogheid Radja Ali Hadji, Onderkoning van Riouw. Vrij vertaald door Dr. P.P. Roorda van Eijsinga, Ridder in de orde van den Nederlandschen Leeuw.

Batavia, ter drukkerij van het Bataviaasch Genootschap. 1848. $8^{\circ}+89$ p.

UBA 487 B 37; UBL C 15 (alleen Nederlandse tekst)

(Titeluitgave van TNI 1847 IV)

9 Vijftiende jaarlijksch verslag van de directie van het Parapattan weezen gesticht, opgericht in het jaar 1832, voor de voeding, kleeding en opvoeding van weezen en andere verlatenen kinderen in dit gedeelte van Indië. Fifteenth Annual Report etc.

Batavia, ter drukkerij van het Bataviaasch Genootschap. 1848. $8^{\circ} .55$ p. (Engelse en Nederlandse tekst)

Perpusnas B 3161848 